\title{
A Drill-free Bone Screw For Intermaxillary Fixation In Military Casualties
}

\author{
AJ Gibbons, JM Baden, AM Monaghan, DK Dhariwal, SC Hodder
}

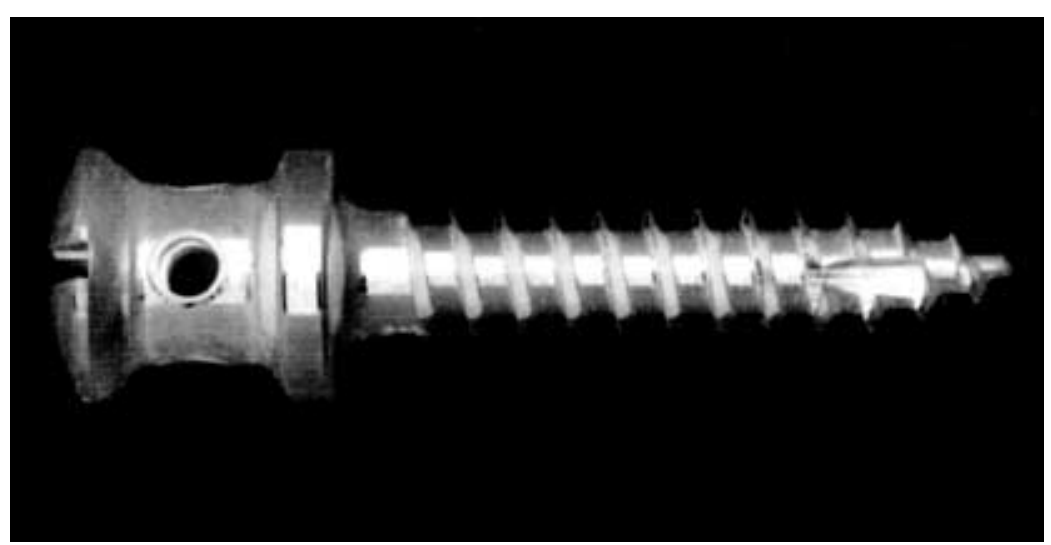

Fig 1. A drill-free intermaxillary fixation screw.

\begin{abstract}
Drill-free bone screws are a simple and quick method of establishing intermaxillary fixation requiring a minimum amount of specialist training or equipment. These screws offer significant advantages over other methods of intermaxillary fixation and are well suited for use in military casualties.
\end{abstract}

\section{Introduction}

BMSc MBBS FDS RCPS RN

General Duties Medical Officer ${ }^{\star}$

Wg Cdr AM Monaghan FDS RCS FRCS RAF Specialist Registrar \#

DK Dhariwal

FDS RCS FRCS

Specialist Registrar +

SC Hodder

FDS RCS FRCS

DipFM

Consultant +

+ Maxillofacial Surgery

Unit, Morriston

Hospital, Swansea,

SA6 6NL

* 40 Commando Royal Marines, Norton Manor

Camp, Taunton,

Somerset, TA2 6PF

\#Department of Oral

and Maxillofacial

Surgery, Queen

Elizabeth Hospital,

Edgbaston,

Birmingham, B15 2TH bonded onto teeth are effective (4) but their use is technique sensitive and they can extrude teeth. Each of these methods of IMF can be difficult and time-consuming to perform. Furthermore, some knowledge of dental materials and anatomy is necessary.

As an alternative to attaching IMF appliances to teeth, pre-drilled bone screws have been developed $(5,6,7)$. These screws are quick to place, reduce the chance of needlestick injury from wires and can be used with heavily restored teeth (5). When drilling the screw holes, saline irrigation assists bone debris removal and cooling of tissues (8). However, there is a risk of the drill damaging the roots of adjacent teeth, especially in inexperienced hands $(9,10,11)$.

To overcome these disadvantages drill free IMF bone screws have recently been introduced. They are particularly suitable for military purposes and we present their use.

\section{Technique}

The drill-free IMF screw (STRATEC Medical Ltd, Welwyn Garden City, AL7 $1 \mathrm{HG}, \mathrm{UK})$ has a specially formed pointed tip (Figure 1).

This enables it to act like a corkscrew and to be pulled into the bone on rotation. The flutes, close to the tip, chisel off bone particles and clear bone swarf away from the pitch of the screw. Hence, the risk of the screw binding and the screw head shearing off during placement is reduced $(12,13)$. The screw is made of threaded $316 \mathrm{~L}$ extra hard stainless steel, has a diameter of $2 \mathrm{~mm}$, and is available in lengths of $8 \mathrm{~mm}$ or $12 \mathrm{~mm}$. The head of the screw is cruciform with a groove beneath it around which wire or elastic IMF may be applied. To obtain more secure IMF two holes penetrate the screw head at right angles through which the IMF fixation may be threaded.

If the patient is awake, adequate anaesthesia of the alveolus, using lignocaine and adrenaline local anaesthetic, must be obtained before inserting the screws. However, this is not necessary if the procedure is performed under general anaesthetic. The IMF screws are placed bicortically, in one step, at the junction of the attached and non-attached gingivae with a cruciform blade screwdriver (Figures 2 and 3). The screws are initially positioned at right angles to the bone surface but as they are advanced they are tilted a few degrees towards the occlusal plane. Hence, 


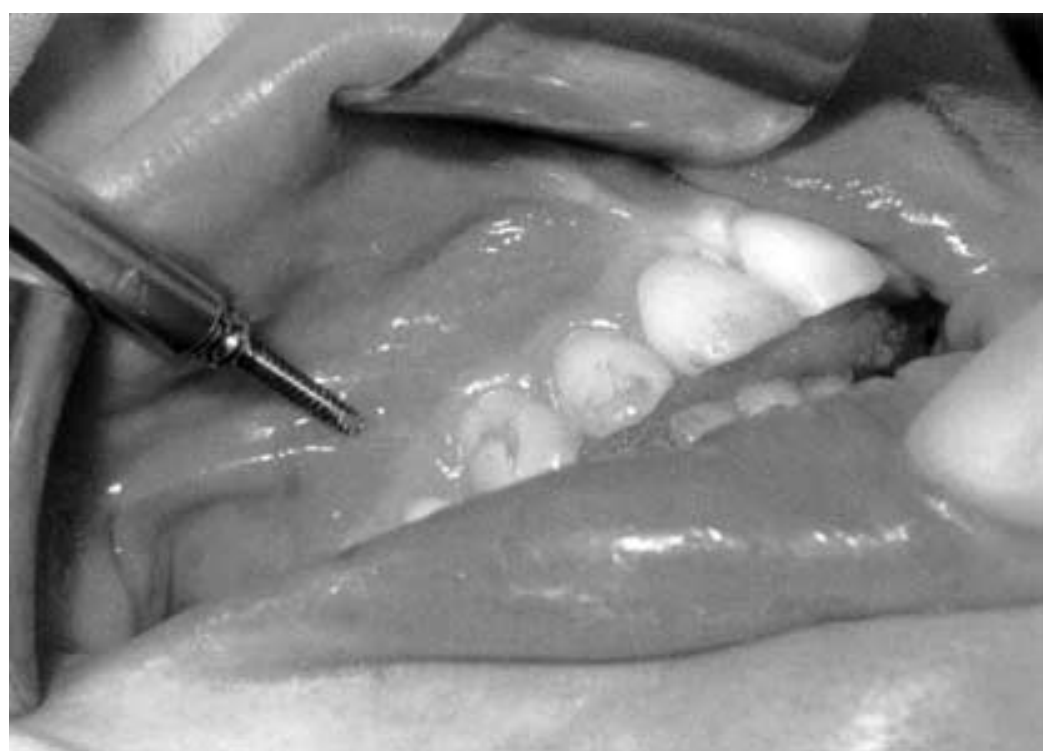

Fig 2. Screw on cruciform screwdriver at level of free and attached mucosa.

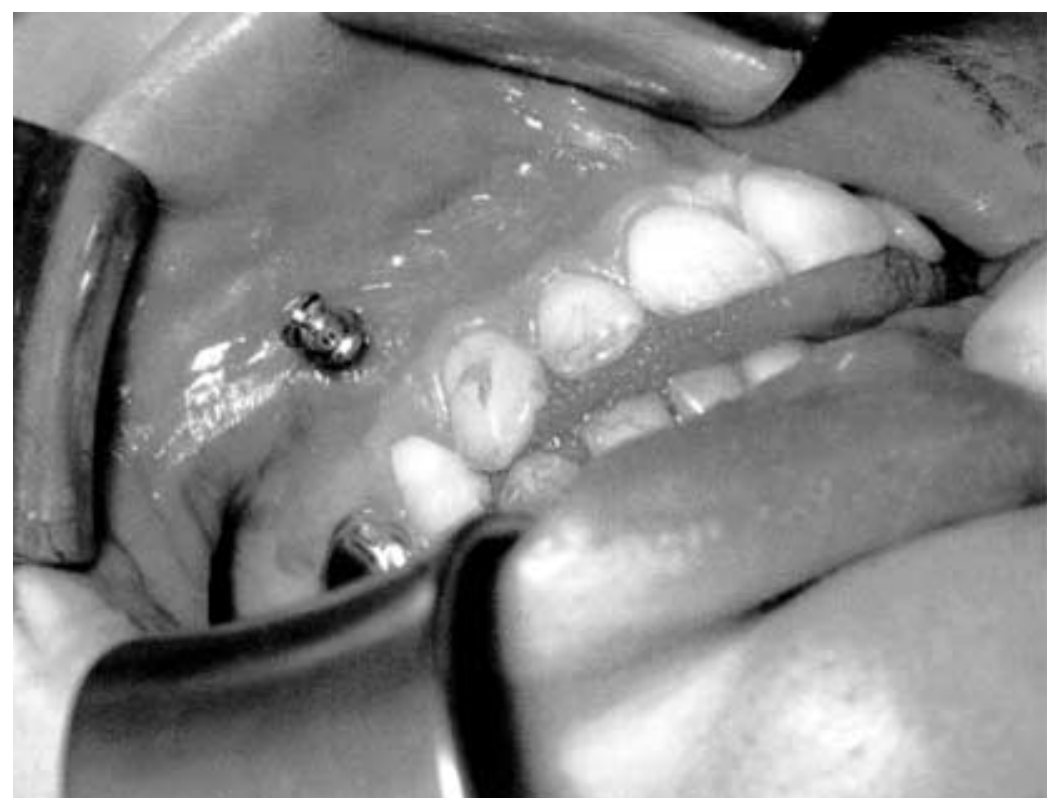

Fig 3. Screw in place between premolars and canine. when fully seated the screws are slightly divergent from each other, preventing any IMF wrapped around the screw heads from slipping off. A little pressure is required to engage the outer cortical plate and some resistance is again felt on engaging the inner plate. Care must be taken to support the bone whist placing the screw, especially with comminuted fractures. If a root is encountered the operator will feel the tip bind. The screw can then be removed and re-sited without significantly damaging the tooth root. Screws can be placed anywhere along the arch but the best position is between the canine and first premolar. Usually one screw per quadrant is sufficient but more can be placed if needed. IMF is preferably established with power chain to reduce the risk of needle stick injury (14) but wire can be used (Figure 4). Once the fractures have healed, the screws can be removed in the outpatient clinic without the need for local anaesthetic.

The screws may be used as temporary IMF to support the fracture during definitive plating. At the end of the operation the IMF is released, the occlusion checked and the screws removed. If postoperative elastic traction is required, for example in mandibular condylar fractures, the screws may be left in place and removed at a later date.

In all cases where screws are left in place, it is very important to check that the sharp tip of the screw has not penetrated through the lingual or palatal alveolar mucosa as this can traumatise the patient's tongue.

The drill-free screw IMF equipment consists of a screwdriver and screws. Hence, its inclusion in the current British Military IMF kit-pack would be a minimal addition.

\section{Discussion}

$16 \%$ of battlefield injuries involve the head and neck region and between 3 and $8 \%$ of all casualties have middle and lower third, facial fractures (15). Providing the airway is secure the evacuation of casualties with facial fractures may not be a priority. However, stabilisation of the fracture to relieve pain and reduce the risk of infection should be performed as soon as possible (16).

The definitive treatment of facial fractures with plating techniques has many benefits. Direct anatomical reduction of the fracture is achieved, mandibular function is restored and the airway remains patent (17). Nevertheless, the use of plates requires specific equipment, theatre time and surgeons trained in the appropriate techniques. On arrival at a field hospital limited resources may preclude early plating of casualties' facial fractures. Therefore, as a simple method of fracture stabilisation, $\mathrm{IMF}$ is frequently used.

Drill-free screws offer significant 
advantages over other forms of IMF when treating simple fractures. The screws are quick and easy to insert and can be used by non-specialist surgeons with minimal training. Their use saves operating time, reduces gingival trauma and the risk of needlestick injury. No complex equipment is required and they can be used even when teeth are heavily restored or damaged. Screws may be placed under local anaesthetic, especially if the reduction of the fracture is straightforward. Moreover, as no drill is used it is difficult to damage teeth.

Drill free screws may be used in comminuted fractures. However, if the number of fracture sites make placement of screws difficult and if multiple screws are required, then conventional eyelet wiring or arch bar techniques should be considered.

In the initial treatment of many facial fractures, drill free bone screws offer a simple quick and easy method of establishing IMF. Hence, they are well suited for use in military casualties.

\section{References}

1. Kilby NG, Blackburn G. In: Field surgery pocket book. London: Her Majesty's Stationary Office 1981: 248-249.

2. Rowe N, Williams JLI. In: Maxillofacial Injuries. Edinburgh: Churchill Livingston 1985: 238.

3. Lloyd T, Nightingale C, Edler R. The use of vacuum-formed splints for temporary intermaxillary fixation in the management of unilateral condylar fractures. Br $\mathcal{F}$ Oral Maxillofac Surg 2001; 39: 301-303.

3. Busch RF. Maxillomandibular fixation with intraoral cortical bone screws: a 2-year experience. Laryngoscope 1994; 104: 1048-1050.

4. Utley DS, Utley JD, Koch RJ, Goode RL. Direct bonded orthodontic brackets for maxillomandibular fixation. Laryngoscope 1998; 108: 1338-1345.
5. Jones DC. The intermaxillary screw: a dedicated bicortical bone screw for temporary intermaxillary fixation, Br F Oral Maxillofac Surg 1999; 37: 115116.

6. Schneider AM, David LR, DeFranzo AJ, Marks MW, Molnar JA, Argenta LC.

Use of specialized bone screws for intermaxillary fixation. Ann Plast Surg 2000; 44: 154-157.

7. Vartanian AJ, Alvi A. Bone-screw mandible fixation: An intraoperative alternative to arch bars. Otolaryngol Head Neck Surg 2000; 123: 718-721.

8. Heidemann W, Gerlach KL. Clinical applications of drill free screws in maxillofacial surgery. $\mathcal{F}$ Cranio-Max Fac Surg 1999; 27: 252-255.

9. Key S, Gibbons A. Letter: Care in the placement of bicortical intermaxillary fixation screws. $\mathrm{Br} \mathcal{F}$ Oral Maxillofac Surg 2001; 39: 484.

10. Majumdar A, Brook IM. Iatrogenic injury caused by intermaxillary fixation screws. $\mathrm{Br} f$ Oral Maxillofac Surg 2002; 40: 84.

11. Coburn DG, Kennedy DWG, Hodder SC. Complications with intermaxillary fixation screws in the management of fractured mandibles. $\mathrm{Br} \mathcal{F}$ Oral Maxillofacial Surg 2002; 40: 241-243.

12. Holmes S, Hutchinson I. Letter: Caution in the use of bicortical intermaxillary fixation screws. $B r$ f Oral Maxilllofac Surg 2000; 38: 574.

13. Farr DR, Whear NM. Intermaxillary fixation screws and tooth damage. BrF Oral Maxillofac Surg 2002; 40: 84-85.

14. Smith A. The use of orthodontic chain elastic for temporary intermaxillary fixation. $\mathrm{Br} \mathcal{F}$ Oral Maxillofac Surg 1993; 31: 250-251.

15. Dobson JE, Newell MJ, Shepherd JP. Trends in Maxillofacial Injuries in War-Time (1914-1986). Br $\mathcal{F}$ Oral Maxillofac Surg 1989; 27: 441-450.

16. Maloney PL, Lincoln RE, Coyne CP. A protocol for the management of compound mandibular fractures based on time from injury to treatment. $\mathcal{F}$ Oral Maxillofac Surg 2001; 59: 879-884.

17. Leach J, Truelson J. Traditional methods vs rigid internal fixation of mandibular fractures. Arch Otolaryngol Head Neck Surg 1995; 121: 750-753. 